\title{
The Potential of Media Excursions as Communication Tool for Promoting Image and Visibility among the Nile Basin Stakeholders
}

\author{
Peres N. Wenje ${ }^{1, *}$, Joseph P. Ngome ${ }^{2}$ \\ ${ }^{I}$ Masinde Muliro University of Science and Technology, Department of Journalism and Mass Communication, \\ Kenya \\ ${ }^{2}$ Health \& Environment Media Network (HEMNet), UK
}

*Corresponding Author: Peres N. Wenje ${ }^{l}$ Masinde Muliro University of Science and Technology, Department of Journalism and Mass Communication, Kenya

\begin{abstract}
Next to oxygen, water and good environment are the other most essential element to human life; the body usually cannot survive longer than a week without water. It is critical to almost every aspects of human endeavour, from agriculture, to industry, to energy. As much as water and environmental resources are important for human survival, rarely are the media headlines devoted to the poignant truth on the diminishing availability of water and environmental resources and the consequences for the future. The same situation prevails in media coverage of activities on the Nile River. A number of challenges have been suggested as responsible for this state of affairs. The fundamental water and environmental issues have not penetrated the consciousness of the public, decision makers and the media to the same degree that surface issues such as politics, trade disputes, sports, business, and food security have. The other is that the interactions of specialists on Nile River Basin and media professionals have been poor. In order to address this problem of poor coverage by the media, NBI in conjunction with NBD established the Nile Media Network (NMN) in each riparian country in 2005. In an attempt to understand this prevailing information gap, researchers from Masinde Muliro University of Science and Technology (MMUST) conducted a study to establish the levels of awareness on Nile River projects among journalists in Kenya in particular and Africa in general. The findings reveal that the level of awareness about Nile Basin projects stands at 39 per cent, suggesting that the Nile River Projects activities are less familiar to the journalists. The present article argues that Nile River publicity in terms of the sources of information about the Nile River comes from media excursions and Interpersonal sources. As a way of improving the prominence of Nile River Basin coverage in the news media, the current study recommends that Nile River Basin stakeholders should organize regular strategic media visits to the projects to provide opportunities for media coverage.
\end{abstract}

Keywords: Nile River, Visibility, Awareness, Media, Excursion

\section{INTRODUCTION}

The media have a critical role to play in facilitating the public understanding of trans boundary Water and Environmental issues. Journalists typically assume the position of "intermediaries" between the water scientist and members of the public who are interested in given water and environmental subject or issue. For this reason, according to Farr (1993), any attempt to understand the social representation of Water and Environmental issues - that is, how Water and Environmental issues is captured in the public imagination - would be incomplete without analysing the media representation of Water and Environmental issues.

Yet in Africa in general and Kenya in particular, very few studies have systematically investigated the volume, quality, scope, and perceptions of the coverage of Water and Environmental issues. One such study by Rooyen (2002) examined the state of Water and Environmental issues coverage in the print media of South Africa. It concluded that there were relatively few Water and Environmental issues articles in the sample of newspapers studied. Some analysts have attempted to examine the factors that account for the type and extent of coverage that Water and Environmental issues get in the media. An analysis in Nature (2009), for instance, attributed these patterns of coverage to the form of expectations that Water and Environmental specialists have towards journalists and vice versa. 
Whereas news organizations in many advanced economies are scaling back significantly on the resources they devote to covering Water and Environmental issues, interest in this field is growing in Africa. According to Irwin (2009), during a major conference on science journalism in 2009, speakers from Africa "were optimistic about a surge of interest in Water and Environmental journalism in their countries" as were their counterparts from the Middle East and Latin America.

\section{THEORETICAL FRAMEWORK}

This article employed framing theory. As developed by Erving Goffman(1974) and Gitlin(1980) it used to explain how media define issues for its customers in terms of both what is significant and how to think about the event. It is certain that scholars have applied framing theory to media research and developed various definitions. The concept of framing remains what Entman (1993) opines as 'a scattered conceptualization', lacking straight forward clear conceptualization that can be generally applicable throughout the social sciences, to political science to linguistics and communication studies.

In this study, framing is defined as a way in which a set of ideas is organized and presented to readership to articulate a particular perspective. Frames are crucial devices that help to organize ideas; so as to make sense of important events and to suggest 'what is at issue' or stake and ' what the event is' . Frames 'define problems', 'diagnose causes', 'make moral judgments' and 'suggest remedies'

Framing involves 'selection, emphasis, and exclusion' of issues. As Robert Entman (1993) interestingly describes,

Framing essentially involves selection and salience. To frame is to select some aspects of a perceived reality and make them more salient in a communicating text, in such a way as to promote a particular problem definition, causal interpretation, moral evaluation, and/or treatment recommendation for the item describe Framing involves highlighting, emphasizing and making some aspects of the issue more memorable, noticeable and meaningful while marginalizing and discarding others. It is a process of categorizing the issue in a specific way, paying more attention to some aspects and disregarding others, and deciding what it means and/or how it came about.

The theory of media framing is highly relevant to the current study of media coverage of Nile River issues in Kenyan print Media in order to analyze the most salient frames that are crucial for determining reader's reception as media frames influence not only the most prominent and salient elements but also interpretations. This can be done through content analysis of articles, which refers to the study of the content of media outlet with reference to the meanings, contexts and intentions contained in it. It is used to extract information, content and categories by objectively identifying specific characteristics of the communication.

\section{OBJECTIVES}

Through a comparative analysis of the coverage of Water and Environmental issues in the selected print media in Kenya, the aims of this study were to:

- To appraise the range of thinking and research about the relationship between Nile River issues and the media.

- To gather empirical evidence on the nature of Nile River issues reporting in the Kenyan media.

- To assess the volume, quality, and scope of Nile River issues coverage in the Kenyan media.

- To examine the conditions that foster and those that impede the coverage of Nile River issues in the Kenyan media.

\section{RESEARCH DESIGN AND METHOdOLOGY}

The study was implemented in Kenya through a combination of qualitative and quantitative approaches. Qualitative assessments based on key informant interviews were employed to gather the opinions of Water specialists, environmentalists, policymakers, and journalists about the coverage of Nile River issues in selected media outlets in the country.

Quantitative assessments were based on content analysis of articles on Nile River issues published in two major national dailies. The newspapers in the sample included two published in English. The 
content analysis yielded some descriptive and some inferential data that gives a detailed and multifaceted picture of the amount of coverage and the characteristics of Nile River reports as measured on various dimensions like tone and source.

\subsection{Data Source}

In this study, both primary and secondary data were collected. The secondary data used was censoriously appraised and collected from relevant literature, databases, as well as internet sources. Further, the data used in this study was drawn from the two leading local dailies in Kenya: The Daily Nation and The Standard for the period of $1^{\text {st }}$ February 2017 to $28^{\text {th }}$ February 2017. The referenced time period is significant on the basis of some observations. The Nile Day which is celebrated annually on $22^{\text {nd }}$ February across Nile Basin countries falls within this period.

The day provides an opportunity to increase awareness on the importance of basin-wide Nile Cooperation. Accordingly, there were many organizations including the Nile basin Initiative (NBI), Nile Basin Discourse (NBD) and Nile Media Network (NMN) who were interested in the media's coverage of the Nile river projects in Kenya. The media was, thus, expected to intensify the coverage of the Nile River projects.

On the source of data, the two dailies were chosen at the exclusion of the others mainly due to their wide reach in terms of circulation and readership, reliability in reporting and detailed approach in presentation of Nile river issues.

\subsection{Population and Sampling Procedures}

Based on the nature of data required for the study and the time and finances allotted, period of $1^{\text {st }}$ February 2017 to $28^{\text {th }}$ February 2017 was picked for this study based on the observation that it is the period when the annual Nile Day event is usually celebrated. For this research, publications between $1^{\text {st }}$ February 2017 to $28^{\text {th }}$ February 2017 were analyzed. A total of 28 publications were analyzed for each paper. This means that every day had an equal chance of being sampled.

\subsection{Unit of analysis}

Units of Analysis are what the researcher counts and assigns categories (Stacks and Hocking, 1998). In this study, the themes that were identified for study and form the unit of analysis includes all articles, news, opinions and commentaries that touched on the Nile River issues in Kenya. Additionally, these included the knowledge of the Nile River projects, functions and mandates of different bodies working on the Nile River issues, conflict arising from the utilization of Nile river resources among others.

Number of articles: This entails all articles on Nile River during the period under consideration and which at the time of study were available to the researcher.

Placement of articles: This is the placement of the articles, opinions or news based in the newspapers. They may appear on the front page, back page or inside.

Type of story: this entails the categories of newspaper items-news, features, editorials, letters-to-the editors, opinions, cartoons, pictures and adverts.

\subsection{Key Informant Interviews}

Interviews were conducted with about 30 key informants - about 5 per Kenya Nile Discourse Forum Focal Points - involved at various levels and to varying degrees in reporting, research, and policymaking on Nile River issues. For consistency across focal points and to ensure meaningful comparison of responses, a standardised interview guide was employed and administered by research assistants familiar with the media in their counties.

Two sets of interview guidelines were used; one for Water and Environmental specialists (see Appendix 1) and one for journalists (see Appendix 2). Many items in the two guidelines are identical. However, the distinctive institutional features of the media industry necessitated the addition of items to capture aspects that are unique to journalism. A separate instrument was therefore found appropriate for this purpose. 
The questions around which the key informants were interviewed were by and large drawn from issues, observations, insights, and criticisms encountered in the literature on the relationship between Nile River, Water and Environment and journalism, communication, and the news media. The investigators surveyed the growing body of literature and thinking (research, analysis, opinions) on such broad subjects as Environmental communication and the public understanding of Water and Environmental issues.

\subsection{Data Collection Procedure}

The researchers obtained a formal letter from Masinde Muliro University of Science and Technology, School of Journalism explaining the objectives of the research. This letter helped the researchers to access and or obtains permission from authorities in Nation Media Group, Kenya National Library as well as The Standard in order to use their resources. The researchers embarked on content analysis of the two newspapers.

\subsection{Data Analysis}

This research employed the use of Excel MS for data analysis. Data that was obtained was then analyzed according to thematic concerns.

\section{WATER, ENVIRONMENTAL ISSUES AND THE MEDIA}

\subsection{Making Sense of the Relationship}

It has long been acknowledged that the media play an important role in society by providing information that is critical to the way people comprehend and make sense of the world in which they live (see for example Hartley, 1996; Luhmann, 2000; McQuail, 2005; O'Shaughnessy \& Stadler, 2008; Erll and Rigney, 2009). The media do these by representing issues, interpreting and evaluating them and in the process helping make sense of the world and events on behalf of their audiences (O’Shaughnessy \& Stadler, 2008).

In terms of Water and Environmental issues, the media are seen as "brokers between Water and Environmental scientists and the public, framing the social reality for their readers and shaping the public consciousness about water and environmental-related events. They are, for many readers, the only accessible source of information about Water and Environmental issues" (Nelkin, 2001: 205). In short, the way people understand Water and Environmental issues is influenced to a significant degree by media coverage, interpretation and presentation.

Several issues determine media coverage of issues and events. One of the commonest factors is that whatever media cover must be newsworthy, and that it must interest a large number of people. In other words, it must appeal by speaking to the news values of significance and relevance (Galtung \& Ruge, 1965; O’Shaughnessy \& Stadler, 2008).

Despite the above arguments, however, some issues are often given a wide berth especially when they are considered complex or of little interest to the majority of society (Stocking, 1999). Unfortunately, Water and Environmental issues are among the areas that the media often pay little attention to. This is based on numerous factors one of them being the assumption that there is little audience interest particularly because Water and Environmental issues are generally difficult to understand both for journalists and audiences.

Thus a majority of what is covered as Water and Environmental issues is often simplistic and designed to appeal to as many people as possible, a phenomenon that can be referred to as the least common denominator approach to coverage. Given the rising commercialisation of media and commoditisation of information, news must have a buyer (Allan, 2004). In essence, it is assumed that the more complicated news is, the fewer buyers or consumers it will attract. This is something most media are aware of and are hardly willing to risk especially when they understand all too well what this means for circulation, readership, listenership and viewership.

What this study and survey of the literature do, therefore, is to appraise the factors that inform media coverage of Nile river issues, and what theoretical arguments can be advanced to explain the apparent dearth of Nile river issues in the African media in general and Kenyan media in particular. The literature suggests that the limited coverage is a consequence of the media seeking to set the agenda, 
to frame issues, and to prime the public to attend to particular issues. It is also a consequence of an ever-fragmenting audience brought about by media liberalisation and competition. The limited coverage could also be a result of modest knowledge of Water and environmental issues within the media (Stocking, 1999).

\section{RESUlTS AND DISCUSSIONS}

\subsection{Newspapers}

A total of 56 newspapers from period of $1^{\text {st }}$ February 2017 to $28^{\text {th }}$ February 2017 were analyzed. The sample was drawn from both the Daily Nation and Standard newspapers. Out of the 56 newspapers, 24 articles were found to match the requirements. Daily Nation had a total of 7 articles that had Nile River articles while Standard had a total of 17 articles with Nile Basin issues and the total was 24. Consequently, the Standard had more articles with Nile Basin issues (63.3\%) while Daily Nation had fewer articles $(36.7 \%)$ (See Fig 1)

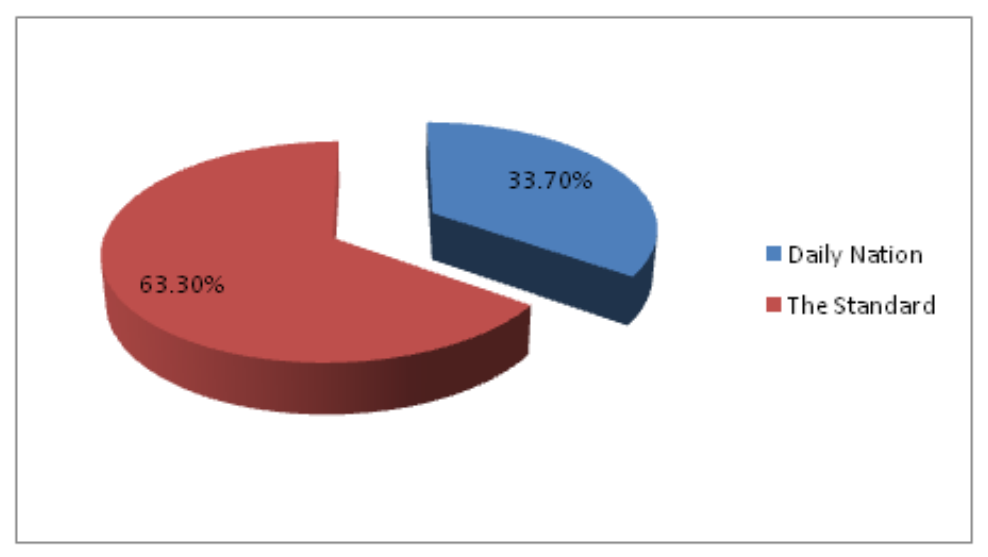

Fig1. Distribution of articles samples in Daily Nation and Standard

Source: Nile River Projects Survey 2017

\subsection{Organization Visibility}

The level of awareness about Nile River Projects was tested using the question "Do you know any Nile River Project in Kenya?" Results depict overall awareness rating of 39 percent, suggesting that the Nile River Projects activities are less familiar to the journalists. (See Fig.2 below).

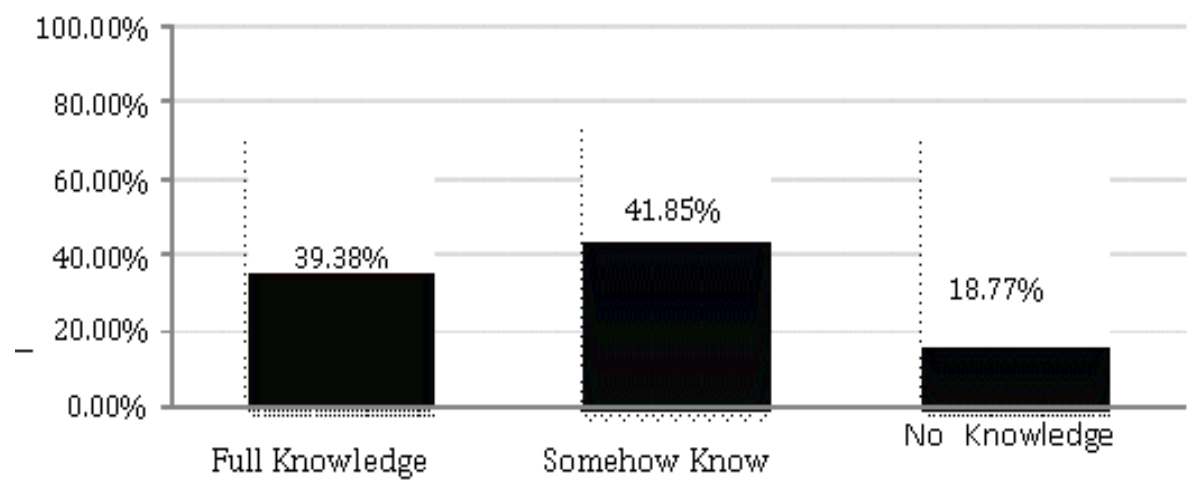

Fig2. Overall awareness index

Source: Nile River Projects Survey 2017

\subsection{Gender Representation of the Coverage}

Fair gender representation in the media is a perennial issue of debate. Men are known to dominate most domains of media practice including in newsrooms and in management. To the extent possible, an attempt was made to identify the gender of each news and information source in every article reviewed. The results as summarized in Table 3 and Figure 4 indicate that $64 \%$ of the 24 articles had only male sources compared to just about $9 \%$ that used only female sources. At least $27 \%$ of the articles used a mix of male and female sources. 
The Potential of Media Excursions as Communication Tool for Promoting Image and Visibility among the Nile Basin Stakeholders

Table3. Gender Representation of Coverage

\begin{tabular}{|l|l|l|}
\hline Gender & Frequency & Percentages \\
\hline Male & 16 & $64 \%$ \\
\hline Female & 3 & $9 \%$ \\
\hline Both Male and Female & 5 & $27 \%$ \\
\hline Totals & $\mathbf{2 4}$ & $\mathbf{1 0 0 \%}$ \\
\hline
\end{tabular}

Source: Nile River Media Coverage Survey 2017

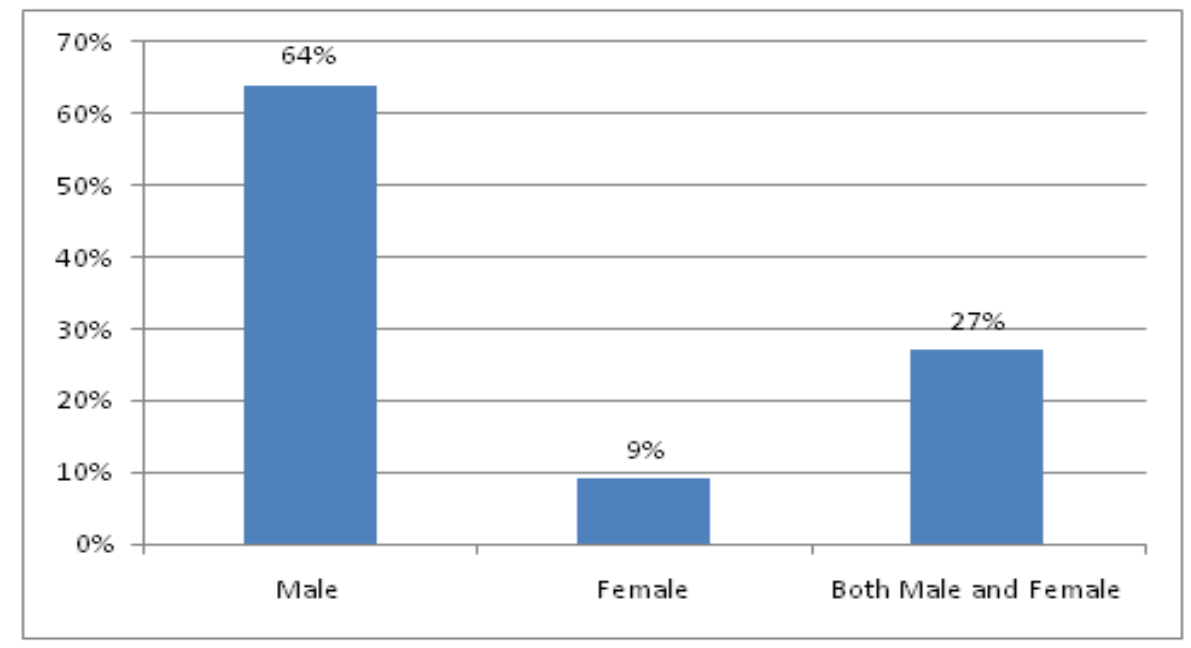

Fig3. Gender Representation of Coverage

Source: Nile River Media Coverage Survey 2017

\subsection{Coverage by the type of Story}

The format of an article was coded as either news or feature, which were the two categories of stories that the study focused on. Their characteristics and distinctions are generally straight forward, which made it relatively easy to pick them out. As shown in Table 1, almost $85 \%$ of the articles were in the category of news while only $15 \%$ were features.

The predominance of news as opposed to feature items resonates with the idea that Nile River stories are likely to get the media's attention if they are first and foremost perceived to be newsworthy. In other words, they often have to compete on the strength of the same news values on which all stories are judged regardless of the topic. In fact, even the decisions that editors make when selecting among stories on Nile River issues seem to be significantly influenced by how current the issues or developments reported are. Currency is ultimately what distinguishes news from other forms of reportage such as features in this particular case. The implication is that Nile River stories stand a better chance of getting of being reported if they qualify as news.

Table4. Format of the Articles

\begin{tabular}{|l|l|l|}
\hline \multicolumn{1}{|c|}{ Prominence } & \multicolumn{1}{c|}{ Frequency } & \multicolumn{1}{c|}{ Percentages } \\
\hline News & 21 & $84.9 \%$ \\
\hline Feature & 3 & $15.1 \%$ \\
\hline Totals & $\mathbf{2 4}$ & $\mathbf{1 0 0 \%}$ \\
\hline
\end{tabular}

Source: Nile River Media Coverage Survey 2017

\subsection{Evaluation of Articles on Event versus Process}

The study looked at the nature of stories by distinguishing between event- and process-oriented reporting. Event-based stories focus on the moment, whereas process-based stories tend to go deeper, to be analytical, and to bring out underlying trends. As the data shows in Table 5, most stories about science and technology were event-based $(72 \%)$ compared to those that were process-based (nearly $28 \%$ ). This finding echoes what was reported earlier regarding the predominant format: news vs. features. News and events go hand-in-hand. It was therefore logical to find that these two characteristics also typified media coverage of Nile River basin issues. 
The Potential of Media Excursions as Communication Tool for Promoting Image and Visibility among the Nile Basin Stakeholders

Table5. Evaluation of Stories in terms of Event versus process

\begin{tabular}{|l|l|l|}
\hline \multicolumn{1}{|c|}{ Nature of Stories } & \multicolumn{1}{c|}{ Frequency } & \multicolumn{1}{c|}{ Percentages } \\
\hline Event & 18 & $72 \%$ \\
\hline Process & 6 & $28 \%$ \\
\hline Totals & $\mathbf{2 4}$ & $\mathbf{1 0 0 \%}$ \\
\hline
\end{tabular}

Source: Nile River Media Coverage Survey 2017

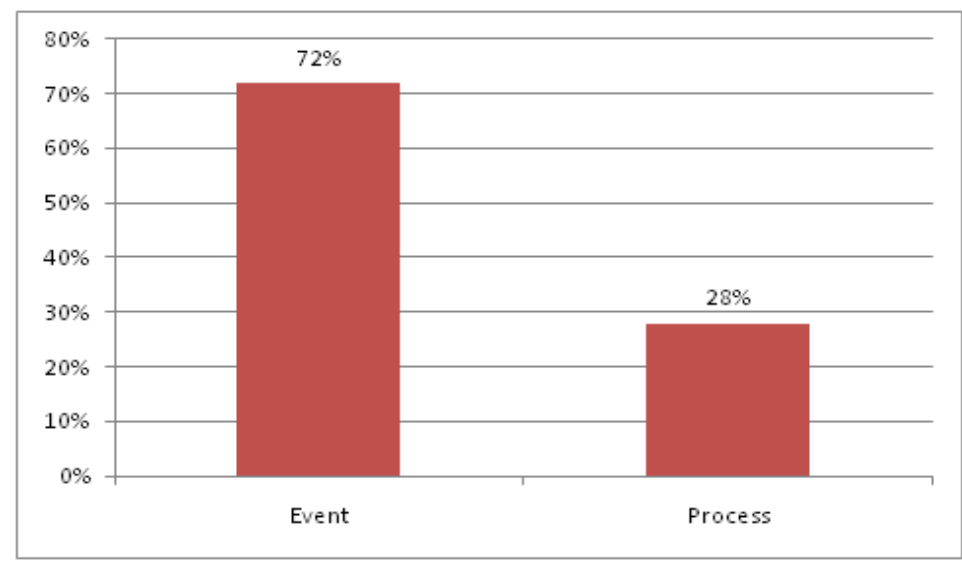

Fig4. Evaluation of Stories in terms of Event versus process

Source: Nile River Media Coverage Survey 2017

\subsection{Sources of Information}

Looking at the effectiveness of different aspects of Nile River publicity in terms of the source of information about the Nile River's array of activities, results present a broad range, including mass media and inter-personal sources. For the most part, media excursions remain the most outstanding sources of information.

Table6. Journalist's sources of Information

\begin{tabular}{|l|l|l|}
\hline Sources of Information & No of Reponses & Percentages \\
\hline Media Excursions & 10 & $40 \%$ \\
\hline Radio & 8 & $34 \%$ \\
\hline Friends/Colleagues & 4 & $15 \%$ \\
\hline Publicity/Boards & 2 & $5 \%$ \\
\hline TV & 1 & $3 \%$ \\
\hline Newspaper & 1 & $2 \%$ \\
\hline Internet & 1 & $1 \%$ \\
\hline Totals & & $\mathbf{1 0 0 \%}$ \\
\hline
\end{tabular}

Source: Nile River Media Coverage Survey 2017

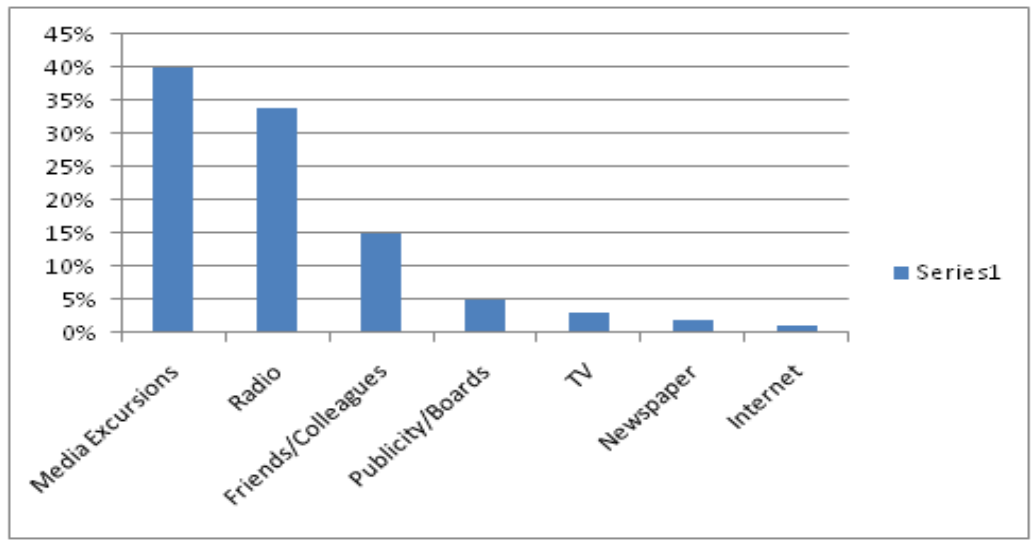

Fig5. Journalist's sources of Information

Source: Nile River Media Coverage Survey 2017 
The Potential of Media Excursions as Communication Tool for Promoting Image and Visibility among the Nile Basin Stakeholders

\subsection{Dominant Topics in the Stories}

The research used certain keywords in order to establish the dominant topics inherent in the stories. Nile River was the keyword that was used in many articles. Nile River conflicts or simply conflict appeared 7 times with a percentage of $28.65 \%$ (See Table 7 and figure 6). Nile River Cooperation appeared 6 times representing about $28.54 \%$ of the total number of stories sampled. Stories on water appeared 5 times which represents 14.38\%, Environment and forest (in River Nile) 4 (6.13\%), Waste Management 2 (9.62\%), Ecology, Biodiversity and Wildlife 1 (2.01\%), Agriculture $5(0.53 \%)$, climate change (4.65\%), Energy 28 (2.96\%) while the rest posted 24 (2.54\%) times.

Table7. Dominant Topics in the Stories

\begin{tabular}{|l|l|l|}
\hline \multicolumn{1}{|c|}{ Key Words } & \multicolumn{1}{c|}{ Frequency } & \multicolumn{1}{c|}{ Percentage } \\
\hline Nile River Conflicts & 7 & $28.65 \%$ \\
\hline Nile River Cooperation & 6 & $28.54 \%$ \\
\hline water & 3 & $14.38 \%$ \\
\hline Environment and Forest & 1 & $6.13 \%$ \\
\hline Waste Management & 2 & $9.62 \%$ \\
\hline Ecology, Biodiversity and Wildlife & 1 & $2.01 \%$ \\
\hline Agriculture & 1 & $0.53 \%$ \\
\hline Climate Change & 1 & $4.65 \%$ \\
\hline Energy & 1 & $4.25 \%$ \\
\hline The rest & 1 & $1.24 \%$ \\
\hline Totals & $\mathbf{2 4}$ & $\mathbf{1 0 0 \%}$ \\
\hline
\end{tabular}

Source: Nile River Media Coverage Survey 2017

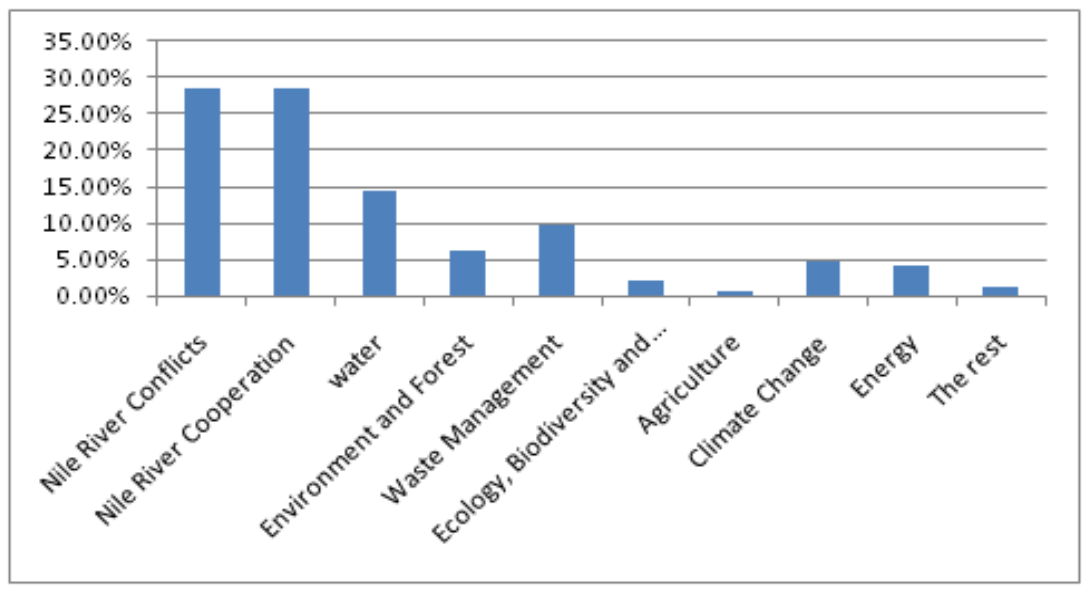

Fig6. Dominant Topics in the Stories

Source: Nile River Media Coverage Survey 2017

The predominance of Nile River conflicts as a media topic stems from the Ethiopian government official announcement of the diversion of the Blue Nile (Abay), to make way for the construction of 'Grand Ethiopian Renaissance Dam' project on 28th May 2013. Since then, the newspapers articles have been presenting and highlighting the struggles or disagreements, and the possible military engagement between Ethiopia and Egypt, which has occupied the nationwide spotlight for some time.

A story in the Standard by Mr Joseph Ngome on February 24, 2017 illustrates:

The riparian states have been embroiled in legal and superiority tussles to replace the old treaties with an all inclusive Cooperative Framework Agreement (CFA) to the chagrin of Egypt and Sudan, who oppose some clauses in the agreement's 38 articles. Due to suspicions among riparian states that have delayed in signing the CFA, Ethiopia without any consultation went ahead and approved the construction of Grand Ethiopian Renaissance Dam (GERD) on the Upper Blue Nile despite protest from Egypt and Sudan. GERD will create a lake 150 square kilometers in size, produce electricity equal to a third of the UAE's energy output and has cost 10 billion Ethiopian birr so far. It will also ensure steady supply of water to the country known to have recurring drought. 
This thematic framing of Nile politics demonstrates the general disagreement between upstream and downstream countries over Nile. It explicitly reproduced this confrontation due to its emphasis on the possibility of Egyptian 'military attack' on Ethiopian dam project, which is understood by the politicians in Cairo as a 'threat' to Egypt's national security, 'water security' in particular.

\subsection{Prominence of coverage}

The stories were also analysed in terms of the prominence or the placement of the story in the news papers. The stories were categorised to be High, Medium or Low (See Table 8 \& Figure 7). High prominent stories were those stories placed on the front or back page, had a headline that mentioned the keywords, devoted more than twenty lines to Nile River basin -specific issue, had a graphic devoted to Nile basin issue in discussion and or was an editorial story. Medium prominent stories had a graphic that integrates Nile river related issue with another issue, graphic that included a Nile River Basin-related issue, a section of an integrated story that devoted 10-20 lines of the story to Nile riverspecific issue and a section of an integrated story that devoted 20 lines of the story to Nile river issue. Low prominent stories had a single mention of five to ten lines devoted to Nile River specific story, a section of an integrated story that devotes 10-20 lines of the story to Nile basin issue and there was no graphic.

Table8. Prominence of coverage

\begin{tabular}{|l|l|l|}
\hline \multicolumn{1}{|c|}{ Prominence } & \multicolumn{1}{c|}{ Frequency } & \multicolumn{1}{c|}{ Percentages } \\
\hline High & 2 & $7 \%$ \\
\hline Medium & 17 & $71 \%$ \\
\hline Low & 5 & $22 \%$ \\
\hline Totals & $\mathbf{2 4}$ & $\mathbf{1 0 0 \%}$ \\
\hline
\end{tabular}

Source: Nile River Media Coverage Survey 2017

Therefore, of the entire sample of 24 articles, the number of stories of Nile River Basin issues placed on the front page, back page or editorial were 2 which is $7 \%$, while medium posted the highest with 17 (71\%) stories. Low focus were 5 (21\%) (See Fig 4).

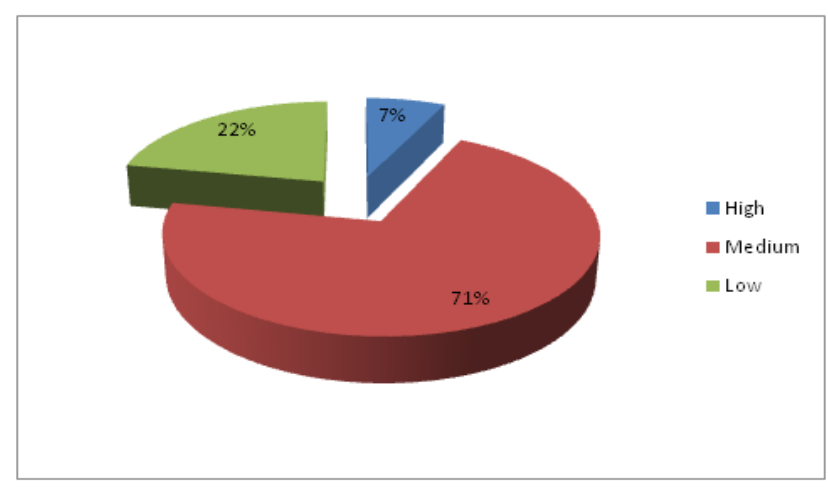

Fig7. Prominence of coverage

Source: Nile River Media Coverage Survey 2017

\subsection{Evaluation of tone Used in the Articles}

The 24 stories were also analyzed in terms of the tone used whether Optimistic, Neutral, Pessimistic or Advocating for Change with regards to Nile River Basin. As shown in Table 9, most of the stories written in both Daily Nation and Standard were neutral.

Table9. Tone Used in the articles

\begin{tabular}{|l|l|l|}
\hline \multicolumn{1}{|c|}{ Tone } & \multicolumn{1}{c|}{ Frequency } & \multicolumn{1}{c|}{ Percentages (\%) } \\
\hline Optimistic & 4 & $14.27 \%$ \\
\hline Neutral & 13 & $52.33 \%$ \\
\hline Pessimistic & 8 & $32.45 \%$ \\
\hline Advocating for Change & 1 & $0.95 \%$ \\
\hline Totals & $\mathbf{2 4}$ & $\mathbf{1 0 0 \%}$ \\
\hline
\end{tabular}

Source: Nile River Media Coverage Survey 2017 
A total of $13(52.33 \%)$ stories were neutral, 4 (14.27\%) were optimistic about Nile river Basin prospects $8(32.45 \%)$ were pessimistic while only $1(0.95 \%)$ stories seemed to advocate for change in terms of Nile river Basin. From the results of this research, the tones of stories varied significantly by their consequences. Pessimistic stories were more likely to emphasize conflicts (32.45\% while stories with optimistic tone were more likely to emphasize benefits (14.27\%). Neutral stories, on the other hand, tended to focus as much as on benefits. Figure 9 shows the distribution of the stories with regards to the tone used.

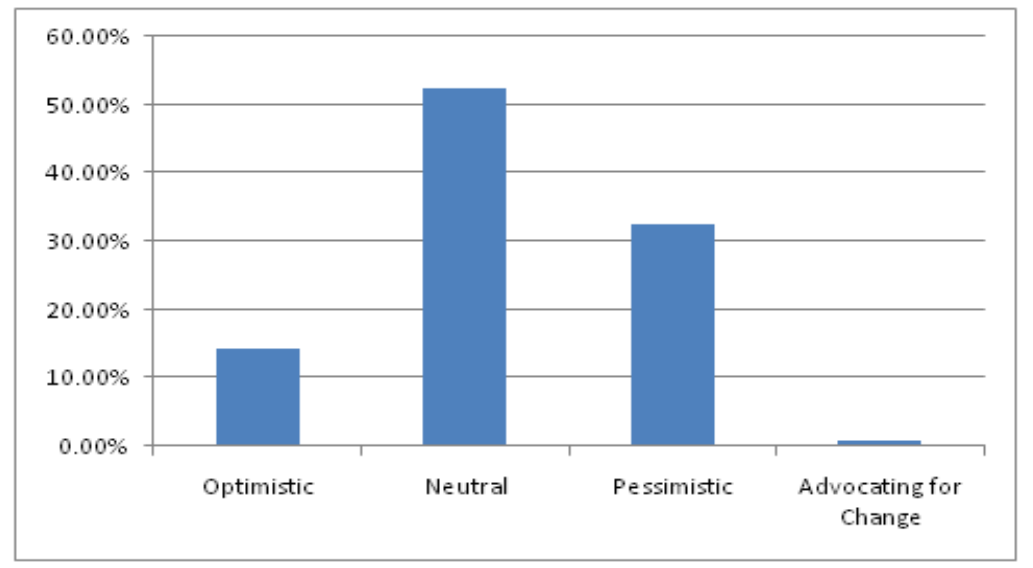

Fig9. Tone Used in the articles

Source: Nile River Media Coverage Survey 2017

\subsection{The Use of Visuals and Infographics}

The entire 24 stories were also analyzed whether they contained pictures or not. The pictures could be for Nile Basin features such as Nile River, Dam Construction activities, Energy production activities. Table 10 and Figure 10 show the summary of the number of articles with pictures or no pictures.

Table 10: The Presence of Pictures

\begin{tabular}{|l|l|l|}
\hline Picture & Frequency & Percentages \\
\hline Yes & 4 & $19.87 \%$ \\
\hline No & 20 & $80,13 \%$ \\
\hline Totals & $\mathbf{2 4}$ & $\mathbf{1 0 0 \%}$ \\
\hline
\end{tabular}

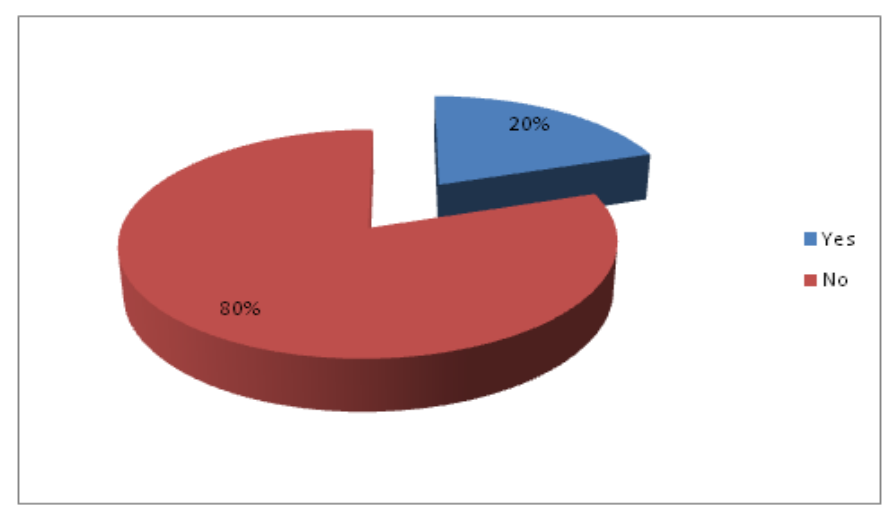

Fig10. Use of Pictures

Source: Nile River Media Coverage Survey 2017

\section{Media Policy AND InVESTMENT IN WATER AND ENVIRONMENT}

From the above exposition, it is clear that water and environmental and Nile River issues in particular are either inadequately covered, or that the coverage is uninformed and sometimes sensational. Results from numerous interviews conducted for this research seem to corroborate claims that the coverage of Nile Basin issues steeped in problems due to various factors, including the quality of coverage brought about by little competence, or lack of specialized knowledge, in water and 
environmental issues. In other words, there are many factors informing the coverage of water and environmental issues. These include media policies and the relationship between, for instance, specialists as sources of information and journalists as conveyors of that information.

First and foremost, this study sought to establish the level of commitment to covering Nile Basin issues by media organizations in Kenya. It was anticipated that this commitment would be reflected (a) in the presence of explicit editorial policies on coverage of water and environmental issues, and (b) in the level of resources invested in building the capacity of journalists to cover the field. Their coverage was informed by availability of water and environmental issues as news, and new information emanating either from news events, reports and sources. This demonstrates that while explicit policies may be lacking, there is sufficient interest especially when media managers, editors and journalists believe that science and technology news would make good reading or if there is sufficient public interest.

It is noteworthy that the issues that capture the attention of the media also attract audiences. This is based on the fact that the media seek to cover issues they think would attract the most number of people as news is increasingly becoming commoditized, and must ultimately find a buyer in a competitive commercial media environment.

However, the minimal coverage that water and environmental and Nile River in particular issues receive can be attributed to lack of capacity coupled with the little investment made by media houses to enhance the competences of their journalists to enable them give science and technology issues informed coverage.

The inability of journalists to give water and environmental issues informed coverage is in part ascribed to gaps in journalism training. This is because there is often little or no balance between academic and vocational courses. Often times the focus is on skills or the craft of journalism.

\section{CONCLUSION}

As evidenced from the arguments advanced herein, there are varied reasons for the dearth of Nile River issues in the Kenyan media. Foremost among these is that water and Environmental issues are often considered complex or that journalists in Kenya lack specialized knowledge and competence to cover them. This is compounded by the fact that despite the limited competence within many newsrooms in Kenya, the media have made little investment in trying to improve the capacity of journalists to enable them give water and Environmental issues informed coverage.

Furthermore, the specialists' community hardly trusts journalists because of the fear of being misquoted or quoted out of context. This is despite the fact that the media and the water and environmentalists community ought to have a symbiotic relationship (scientists as sources and the media as interpreters and disseminators of the information). This is of course not peculiar to Kenya although it demonstrates a worrying trend where issues considered of 'little' public interest, however vital to society, are hardly covered. As this study found, politics and other 'more interesting' issues are often given more and better coverage and space in Kenya's media.

On the bright side, however, this research found out that the frosty relationship between journalists and Water and environmental scientists may now be changing. Thanks to media excursions through organizations such as Nile Media Network, The Open Water Diplomacy Lab among others. Their dealings with journalists have improved although the levels of such engagement still remain low, and may be limited to being sources of information, and, occasionally, analysts. The new relationships are based on the fact that journalists need to support their stories with authoritative voices or experts, as well as access to experts who are willing to give information and to share their perspectives on an issue. Fortunately, some are always willing to talk.

The study also found that common values underpinning media operations like commercialism, sensationalism, and negativity also apply to the reporting of water and Environmental in Kenya. Such coverage is also informed by the level of understanding of the issues; time and space limitations; news format requirements; editorial control; human interest; policy activity on an issue; resonance with and relevance to audiences; dramatic occurrences; and controversy. The foregoing issues are compounded by the fact that whilst there are news organizations with policies informing water and Environmental reporting, most of Kenya's media do not have explicit policies or guidelines on how to cover these important issues. 
Despite the bleak picture painted above, some media organizations in Kenya have done quite well, and continue to improve. For instance, the media in Kenya have been at the forefront of educating the public on HIV/AIDS by persistently, consistently and accurately conveying basic scientific information about transmission of the disease. In focusing on such information, the media can affect the scope and form of public knowledge, values, and action via their agenda setting, issue framing, and audience priming functions.

Similarly, the media in Kenya have in one way or another covered and primed the public's interest in water and Environmental. However, when this is done it is not because of water and Environmental issues per se but because of some controversy that involves such matters. In other words, water and Environmental issues by themselves do not seem to evoke that much interest unless they are also associated with some controversy. Water and Environmental are likely to attract significant public interest when they resonate with the traditional news values - that is, those attributes of the news that tend to attract people to journalistic products in the first place.

\section{RECOMMENDATIONS}

First, the media should have explicit policies and guidelines informing the coverage of water and Environmental issues. This would ensure a proactive approach in looking for and publishing stories relating to the two areas. This will also ensure that water and Environmental issues are given space or airtime whenever they arise. This may also mean a dedicated team of journalists is encouraged to look for such stories. This will no doubt raise the profile of water and Environmental issues and undoubtedly encourage journalists to take it up as a beat.

Second, given the little competence or lack of specialized knowledge of water and Environmental issues, it is important for media organizations to invest in people with water and Environmental backgrounds rather than those with only journalistic knowledge and skills. This will ensure meaningful coverage of water and Environmental issues. If this is not possible, it is important that the media and editors seek expert knowledge and cultivate relationships with experts which will increase the chances for better coverage of water and Environmental issues. Employing or investing in people with expert knowledge of water and Environmental issues may also repair the damage caused by the apparent miscommunication and exaggeration of these issues and this may in turn improve the relationship between the media and the water and environmental research community.

Lastly, the media industry should work closely with training institutions to introduce water and environment curricula as a way of improving the understanding of water and environment issues. Such a foundation is crucial to long-term interest in the field and improvement in its coverage.

\section{REFERENCES}

[1] Allan, Stuart (2004) News Culture. 2nd ed. Maidenhead: Open University.

[2] Anderson, Alison, Petersen, Alan and David, Matthew (2005) 'Communication: Critical Issues. Maidenhead: Open University.

[3] Bauer, Martin (1994) 'Science and Technology in the British Press: 1946-1986'.

[4] Benford, Robert (1993) 'You Could Be the Hundredth Monkey: Collective Action Frames and Vocabularies of Motive within the Nuclear Disarmament Movement'. The Sociological Quarterly, 34. 195-216.

[5] Brighton, Paul and Foy, Dennis (2007) News Values. London: Sage.

[6] Bubela, Tania and Caulfield, Timothy (2004) 'Do the Print Media "hype" Genetic Research? A Comparison of Newspaper Stories and Peer-Reviewed Research Papers'. CMAJ, 170 (9). 1399-1407.

[7] Caulfield, Timothy (2004) 'The Commercialisation of Medical and Scientific Reporting'. PLoS Med, 1 (3). 38.

[8] Entman, Robert (1993) 'Framing: Toward Clarification of a Fractured Paradigm'. Journal of Communication, 43. 51-58.

[9] Erll, Astrid and Rigney, Ann (eds.) (2009) Mediation, Remediation, and the Dynamics of Cultural Memory. Berlin: Walter de Gruyter.

[10] Farr, Robert M. (1993) 'Common Sense, Science and Social Representations'. Public Understanding of Science, 2. 189-204.

[11] Galtung, Johan and Ruge, Mari Holmboe (1965) 'The Structure of Foreign News: The Presentation of Congo, Cuba and Cyprus Crises in Four Norwegian Newspapers', Journal of International Peace Research, 1. 64-90. 
The Potential of Media Excursions as Communication Tool for Promoting Image and Visibility among the Nile Basin Stakeholders

[12] Gamson, William, Croteau, David, Hoynes, William and Sasson, Theodore (1992) 'Media Images and the Social Construction of Reality'. Annual Review of Sociology, 18. 373-393.

[13] Gephart Jr., Robert (2004) 'Sensemaking and New Media at Work'. American Behavioral Scientist, 48 (4). 479-495.

[14] Gitlin T (1980) The whole world is watching: Mass media in the making and unmaking of the new left. University of California Press, Berkeley.

[15] Goffman E (1974) Frame analysis: An essay on the organization of experience. Harvard University press, Cambridge.

[16] Harriet, Buckeley (2000) 'Common Knowledge? Public Understanding of Climate Change in Newcastle, Australia'. Public Understanding of Science, 9. 313-333.

[17] Hartley, John (1996) Popular Reality: Journalism, Modernity and Popular Culture. London: Arnold.

[18] Irwin, A. (2009) 'Science Journalism 'Flourishing' in Developing World' [Online]. Available at $<$ http://www. scidev.net/en/science-communication/science journalism/news/science-journalismflourishing-in-developing-wo rld.html> [1 March 2011].

[19] Kameri-Mbote, P (2005) From Conflict to Cooperation in the Management of Trans-boundary Waters: The Nile Experience Linking Environment and Security - Conflict Prevention and Peace Making in East and Horn of Africa.

[20] Kennedy, Donald and Overholser, Geneva (2010) 'Preface' in Kennedy, Donald and Overholser, Geneva (eds.) (2010) Science and the Media. Cambridge, MA: American Academy of Arts and Sciences. vii- xi.

[21] Lang, Gladys Engel and Lang, Kurt (1983) The Battle for Public Opinion. New York: Columbia University Press.

[22] McCombs, Maxwell and Shaw, Donald (1972) 'The Agenda Setting Function of Mass Media'. Public Opinion Quarterly, 36 (2). 176-187.

[23] McQuail, Denis (2005) Mass Communication Theory, 5th ed. London: Sage.

[24] Nature (2009) ‘Cheerleader or Watchdog?’ Nature 459(7250). 1033.

[25] Nelkin, Dorothy (2001) 'Beyond Risk: Reporting about Genetics in Post-Asilomer Press'. Perspectives in Biology and Medicine, 44 (2). 199-207.

[26] O’Shaughnessy, Michael and Stadler, Jane (2008) Media and Society, 4th ed. Victoria: Oxford.

[27] Ransohoff, David (2001) 'Sensationalism in the Media: When Scientists and Journalists may be Complicit Collaborators'. Effective Clinical Practice, 4. 185-188.

[28] Rooyen, Carine van (2002) 'A Report on Science and Technology Coverage in the SA Print Media'. Foundation for Education, Science and Technology.

[29] Russell, Cristine (2010) 'Covering Controversial Science: Improving Reporting on Science and Public Policy’ in Kennedy, Donald and Overholser, Geneva (eds.) (2010) Science and the Media. Cambridge, MA: American Academy of Arts and Sciences. 13-43.

[30] Science and Media Expert Working Group (2011) 'Science and the Media: From Ideas to Action' [online]. Inspiring Australia Expert Working Group on Science and the Media. Available at <http://www.innovation .gov.au/> [10 May 2011].

[31] Stocking, S. Holly (1999) 'How Journalists Deal with Scientific Uncertainty' in Friedman, Sharon, Dunwoody, Sharon and Rogers, Carol (eds.) (1999) Communicating Uncertainty: Media Coverage of New and Controversial Science. Mahwah, NJ. Lawrence Erlbaum Associates. 23-42.

Citation: Peres N. Wenje, Joseph P. Ngome. "The Potential of Media Excursions as Communication Tool for Promoting Image and Visibility among the Nile Basin Stakeholders". International Journal of Media, Journalism and Mass Communications (IJMJMC), vol 4, no. 1, 2018, pp. 1-13. doi:http://dx.doi.org/10. 20431/2455-0043.0501001.

Copyright: (C) 2018 Authors. This is an open-access article distributed under the terms of the Creative Commons Attribution License, which permits unrestricted use, distribution, and reproduction in any medium, provided the original author and source are credited. 